\title{
High Prevalence of Psychotropics Overdose among Suicide Attempters in Korea
}

\author{
Jinyoung $\mathrm{Kim}^{1}$, Minseob $\mathrm{Kim}^{1}$, Yoo-ra Kim${ }^{1}$, Kyoung Ho Choi ${ }^{2}$, Kyoung-Uk Lee ${ }^{1}$ \\ Departments of ${ }^{1}$ Psychiatry and ${ }^{2} E$ mergency Medicine, Uijeongbu St. Mary's Hospital, College of Medicine, The Catholic University of \\ Korea, Seoul, Korea
}

\begin{abstract}
Objective: The availability of suicide methods affects the risk of suicide attempts. This study examined the patterns of substances ingested by suicide attempters (SAS) and the characteristics of SAs using psychotropic overdoses.

Methods: Data for 384 of the 462 eligible SAs who used self-poisoning were analyzed. Demographic variables, clinical characteristics, and factors related to the suicide attempts were examined.

Results: There were 256 (66.7\%) females and 128 (33.3\%) males. Roughly half the SAs ingested psychotropics ( $n=179,46.6 \%)$. Agricultural chemicals ( $n=84,21.9 \%$ ) were the second most frequently ingested substances, followed by analgesics $(n=62,16.1 \%)$, household products ( $n=27,7.0 \%)$, and other prescribed medications ( $n=23,6.0 \%)$. Among psychotropics, the most frequently overdosed drugs were sedative-hypnotics, including hypnotics $(n=104)$ and benzodiazepines $(n=78)$. SAs favored $Z-d r u g s$ and alprazolam. When compared with SAs with non-psychotropic overdoses, significantly more SAs with psychotropic overdoses were female (76\% vs. 58.5\%, $p<0.001)$ and had a psychiatric history $(59.8 \%$ vs. $29.8 \%, p<0.001)$. They had significantly more previous suicide attempts $(0.52 \pm 1.02$ vs. $0.32 \pm 0.80, p<0.05)$ and lower risk $(7.96 \pm 1.49 \mathrm{vs} .8 .44 \pm 1.99, p<0.01)$ and medical severity (3.06 \pm 0.81 vs. $3.37 \pm 0.93, p<0.005)$ scores.

Conclusion: Psychotropic overdose, especially with sedative-hypnotics, was a major method in suicide attempts. It is important that psychiatric patients are carefully evaluated and monitored for suicidality when prescribing psychotropics.
\end{abstract}

KEY WORDS: Attempted suicide; Drug overdose; Psychotropic drugs; Hypnotics and sedatives.

\section{INTRODUCTION}

Studies of the choice of method used in suicidal behavior are important because the prevalence and outcome of suicide attempts are determined by the availability and lethality of the attempted method. ${ }^{1-3)}$ Among suicide methods, self-poisoning or overdose is frequently chosen. ${ }^{4)}$

Few studies have examined the substances used by suicide attempters (SAs). In the US and Australia, tricyclic antidepressants (TCAs), benzodiazepines (BDZs), alcohol, cocaine, and amphetamine were the most commonly overdosed drugs. ${ }^{5-7)}$ In Canada, psychotropic drugs, other prescription medications, and over-the-counter (OTC) medications were frequently ingested for suicide. ${ }^{8)}$ Analgesics, antidepressants, alcohol, and sedative-hypnotics were common causes of fatal poisoning in England and Wales. ${ }^{9)}$

Received: August 20, 2015 / Revised: September 28, 2015 Accepted: October 4, 2015

Address for correspondence: Kyoung-Uk Lee, MD, PhD Department of Psychiatry, Uijeongbu St. Mary's Hospital, College of Medicine, The Catholic University of Korea, Banpo-daero, Seocho-gu, Seoul 06591, Korea

Tel: +82-31-820-3609, Fax: +82-31-847-3630

E-mail: mindcure@catholic.ac.kr
In Korea, commonly ingested drugs were psychotropics, pesticides, prescribed medications, and analgesics. ${ }^{10,11)}$

Because psychiatric disorders are major contributing factors to suicide, it is not surprising that psychotropic drugs were the drugs most commonly used by SAs. ${ }^{8)}$ Antidepressants, especially TCAs and sedative-hypnotics, often account for suicide death by overdose. ${ }^{7-9,12,13)}$ Sedative-hypnotics are associated with an increased risk of suicide in the elderly. ${ }^{14,15)}$ In Korea, sedative-hypnotics, including BDZs and Z-drugs, are frequently prescribed, and the prevalence was relatively higher than that in other countries. ${ }^{16)}$ The availability of these medications might affect the pattern of psychotropics used by SAs, although there have been no reports in this regard.

Only a few studies have examined the types of substance used by SAs, and fewer have investigated the factors associated with overdoses with different types of medication. For example, the use of pesticides was more notable in elderly SAs living in a rural area, ${ }^{11)}$ and analgesics were frequently used by young adolescents. ${ }^{10)}$ Studies have shown that women succumb to drug overdose more often than men. ${ }^{5,9)}$ 
Interventions to reduce mortality from drug overdose must focus on targeting substances that are frequently taken or frequently lethal in such situations. Therefore, studies examining substances used by SAs and the characteristics of those SAs may provide valuable information for treatment and prevention of suicide.

Therefore, this study examined the pattern of substances used by SAs in Korea to overdose and investigated the characteristics of SAs who overdosed using psychotropics, which were the drugs ingested most frequently.

\section{METHODS}

\section{Study Population}

Data were obtained from a retrospective review of the charts of medical and psychiatric patients admitted to the emergency department (ED) of Uijeongbu St. Mary's Hospital, the Catholic University of Korea from January 2008 to December 2009. Patients were included if information given by the patients themselves or objective information from their rescuers confirmed that they had attempted suicide. This study was approved by the institutional review board of The Catholic University of Korea, Uijeongbu St. Mary’s Hospital (IRB No. XC12RIME0141U).

\section{Procedures and Assessment Instruments}

All patients admitted to the ED after attempting suicide were referred to psychiatry residents, and a comprehensive interview was conducted in the ED. During the interview, a complete mental examination was performed. Information about demographic and clinical characteristics and the presenting suicidal behavior were also collected.

Psychiatric diagnoses were made by psychiatry residents using the criteria from the Diagnostic and Statistical Manual of Mental Disorders-IV text revision. ${ }^{17)}$ Detailed data about the presenting suicide attempt, such as established suicide risk factors and responses to reliable and valid scales measuring risk/rescue were also obtained. ${ }^{18)}$ The risk/rescue scale consists of 10 items: five items assessing risk factors and five assessing rescue factors. ${ }^{19)}$ Higher risk scores indicate that the patient's suicide attempt was more serious, whereas higher rescue rating scores suggest that the patient made a less serious, more reversible suicide attempt.

Medical severity was assessed using the medical risk of death included in the Suicide Attempt Self-Injury Interview developed and validated by Linehan et al. ${ }^{20)}$ The scores ranged from 1 to $6(1=$ very low, $2=$ low, $3=$ moder- ate, $4=$ high, $5=$ very high, $6=$ severe). An increase in the medical severity score implies the suicide risk carried a high risk of mortality.

A toxicology report including ingested substances was obtained by the ED residents when SAs arrived at the ED. The substances were classified as psychotropics, agricultural chemicals, analgesics, household products, prescribed medications, and others. Psychotropics included antidepressants (selective serotonin reuptake inhibitors [SSRIs], serotonergic and noradrenergic reuptake inhibitors [SNRIs], TCAs, and others [e.g., mirtazapine, trazodone, and bupropion]), sedative-hypnotics (BDZs, Z-drugs [zolpidem], and OTC hypnotics [doxylamine and diphenhydramine]), and antipsychotics, and mood stabilizers (valproic acid, lithium, and carbamazepine). Agricultural chemicals included herbicides, fungicides, and insecticides. Analgesics included acetaminophen, aspirin, and opioid analgesics. Household products included acetic acid, sodium hypochlorite, and lye. All other prescription medication such as beta-blockers, calcium-channel blockers, antidiabetics, and antibiotics were considered prescribed medications. Others included toxic plants, herbs, and herbal preparations.

\section{Statistical Analysis}

Of the 468 patients with suicide attempts by self-poisoning, data for 384 eligible patients were analyzed. Data for 78 patients were excluded due to refusal of a psychiatric interview $(\mathrm{n}=51,11.0 \%)$, serious medical condition $(\mathrm{n}=24,5.1 \%)$, and incomplete medical information $(\mathrm{n}=3$, $0.6 \%$ ). Means and frequencies were calculated according to variable type. In terms of the psychiatric diagnosis, only the principal diagnosis was considered. To calculate the number of ingested psychotropics in cases involving multiple drug ingestion, psychotropics were added for each psychotropic classification. To compare SAs who used psychotropics to overdose with those who used non-psychotropics to do so, $t$-tests and chi-square analyses were performed as appropriate. Analysis of variance (ANOVA) and post-hoc tests were performed on age to estimate differences according to substances. The statistical analyses were conducted using the Statistical Analysis System ver. 9.2 (SAS Institute, Cary, NC, USA).

\section{RESULTS}

\section{Demographic and Clinical Characteristics}

The mean age of the SAs was $43.9 \pm 16.9$ (range 11-94) years. There were twice as many females as males (256 
[66.7\%] vs. 128 [33.3\%]). Most ( $\mathrm{n}=214,55.7 \%)$ respondents were married, followed by single $(\mathrm{n}=105,27.3 \%)$, widowed $(\mathrm{n}=38,9.9 \%)$, and divorced $(\mathrm{n}=27,7.0 \%)$.

Unipolar depression was the most common psychiatric diagnosis among SAs with drug overdoses $(\mathrm{n}=327$, $85.2 \%)$, followed by adjustment disorder ( $\mathrm{n}=25,6.5 \%)$, bipolar depression $(\mathrm{n}=12,3.1 \%)$, alcohol-related disorders $(\mathrm{n}=11,2.9 \%)$, and schizophrenia $(\mathrm{n}=8,2.1 \%)$.

Interpersonal problems were the leading cause of suicide attempts $(\mathrm{n}=226,58.9 \%)$, followed by economic problems $(n=46,10.7 \%)$, physical illnesses $(n=34,8.6 \%)$, and work stress $(n=16,3.9 \%)$. Other problems $(n=51$, $13.3 \%)$ and unknown reasons $(\mathrm{n}=18,4.7 \%)$ were also noted.

\section{Patterns of Overdose Substances by Classification}

About half the SAs ingested psychotropics $(\mathrm{n}=179$, $46.6 \%)$. Agricultural chemicals $(n=84,21.9 \%)$ were the second most frequently ingested substances, followed by analgesics $(n=62,16.1 \%)$, household products $(n=27$, $7.0 \%)$, and other prescribed medications $(\mathrm{n}=23,6.0 \%)$ (Fig. 1).

Among psychotropics, the most commonly overdosed drugs were sedative-hypnotics, including hypnotics (104 cases) and BDZs (78 cases). Zolpidem was the hypnotic used most frequently ( 57 cases, $54.8 \%$ ), followed by OTC hypnotics (doxylamine: 23 cases [22.1\%], diphenhydramine: 5 cases [4.8\%]), and triazolam (14 cases, $13.5 \%$ ). Alprazolam was the BDZs used most commonly (21 cases, $26.9 \%$ ), followed by lorazepam (12 cases, $15.4 \%$ ), clonazepam (11 cases, 14.1\%), diazepam (5 cases, 6.4\%), and unknown BDZs (29 cases, 37.2\%).

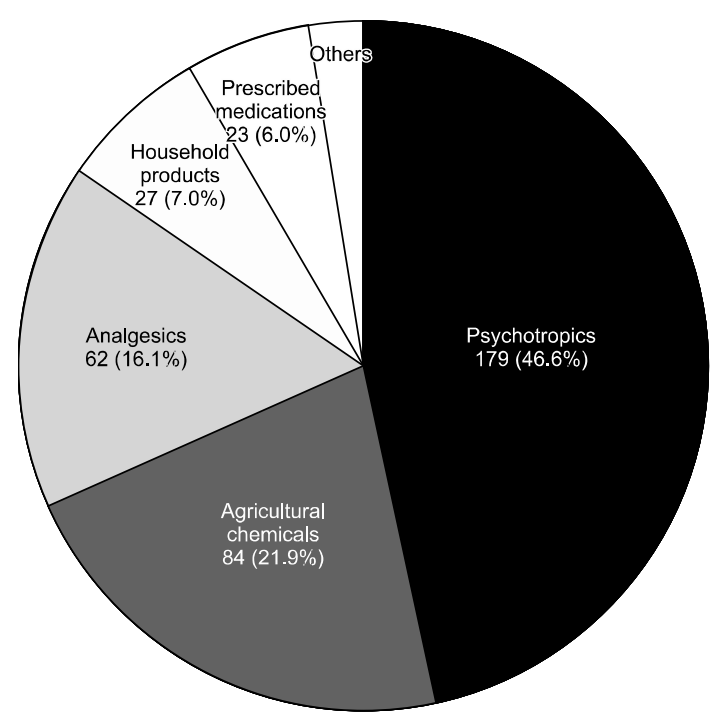

Fig. 1. Proportions of overdosed substances by classification.
Among antidepressants, SSRIs were the most common ( 25 cases, $53.2 \%$ ), followed by TCAs ( 15 cases, $31.9 \%$ ). Fig. 2 summarizes the details of the psychotropics ingested by SAs.

\section{Clinical Differences between SAs according to Use of Psychotropics and Non-psychotropics}

We next compared the clinical characteristics of SAs according to whether psychotropic or non-psychotropic medications were used for the attempt. Table 1 summarizes the demographic data and clinical characteristics of the two groups.

In comparison with SAs who used non-psychotropic medications, those who used psychotropic medications to overdose were significantly more likely to be female ( $76 \%$ vs. $58.5 \%, p<0.001)$ and have a psychiatric history $(59.8 \%$ vs. $29.8 \%, p<0.001)$. They also had significantly more previous suicide attempts $(0.52 \pm 1.02$ vs. $0.32 \pm 0.80$, $p<0.05)$ and low scores for risk $(7.96 \pm 1.49$ vs. $8.44 \pm$ $1.99, p<0.01)$ and medical severity $(3.06 \pm 0.81$ vs. $3.37 \pm 0.93, p<0.005)$. They did not differ significantly with regard to the other variables.

\section{Relationship between Age and Substance Used for Overdose}

The mean patient age differed significantly according to the class of substances used for the overdose ( $\mathrm{F}[5$, $378]=16.23, p<0.001)$. Post-hoc analysis revealed that the SAs who ingested analgesics $(30.4 \pm 11.7)$ were sig-

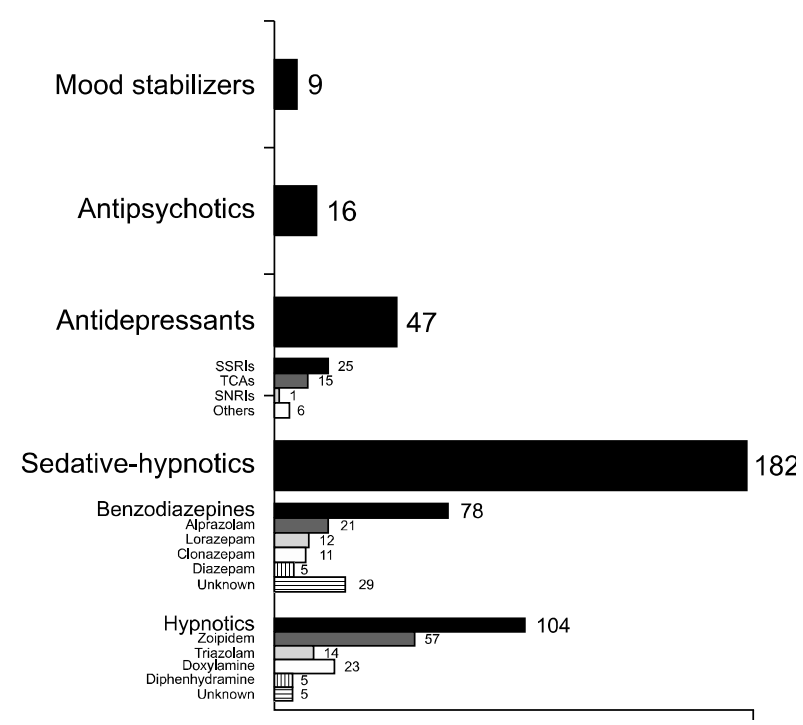

Fig. 2. Cases of psychotropics ingested by suicide attempters. SSRI, selective serotonin reuptake inhibitors; TCAs, tricyclic antidepressants; SNRI, serotonergic and noradrenergic reuptake inhibitors. 
Table 1. The difference of demographic and clinical factors between psychotropic overdose and non-psychotropic overdose suicide attempters

\begin{tabular}{|c|c|c|c|c|}
\hline Variable & $\begin{array}{l}\text { Psychotropic overdose } \\
\qquad(n=179)\end{array}$ & $\begin{array}{l}\text { Non-psychotropic overdose } \\
\qquad(n=205)\end{array}$ & $\begin{array}{c}\text { Statistics } \\
\text { († or chi-square) }\end{array}$ & $p$ value \\
\hline Age $(y r)$ & $45.2 \pm 16.4$ & $42.8 \pm 17.2$ & 1.375 & 0.170 \\
\hline Sex & & & 13.081 & $<0.001$ \\
\hline Male & $43(24.0)$ & $85(41.5)$ & & \\
\hline Female & $136(76.0)$ & $120(58.5)$ & & \\
\hline Marriage & & & 4.034 & 0.258 \\
\hline Single & $41(22.9)$ & $64(31.2)$ & & \\
\hline Married & $103(57.5)$ & $111(54.1)$ & & \\
\hline Divorced & $15(8.4)$ & $12(5.9)$ & & \\
\hline Widowed & $20(11.2)$ & $18(8.8)$ & & \\
\hline Comorbid medical illnesses & & & 0.256 & 0.613 \\
\hline Yes & $62(34.6)$ & $66(32.2)$ & & \\
\hline No & $117(65.4)$ & $139(67.8)$ & & \\
\hline Past psychiatric history & & & 34.995 & $<0.001$ \\
\hline Yes & $107(59.8)$ & $61(29.8)$ & & \\
\hline No & $72(40.2)$ & $144(70.2)$ & & \\
\hline Numbers of previous suicide attempts & $0.52 \pm 1.02$ & $0.32 \pm 0.80$ & 2.176 & $<0.05$ \\
\hline Reattempt or not & & & 5.306 & $<0.05$ \\
\hline Yes & $54(30.2)$ & $41(20.0)$ & & \\
\hline No & $125(69.8)$ & $164(80.0)$ & & \\
\hline Risk rating score & $7.96 \pm 1.49$ & $8.44 \pm 1.99$ & 2.687 & $<0.01$ \\
\hline Rescue rating score & $12.07 \pm 2.16$ & $12.35 \pm 1.96$ & 1.325 & 0.186 \\
\hline Medical severity & $3.06 \pm 0.81$ & $3.37 \pm 0.93$ & 3.490 & $<0.005$ \\
\hline Planning & & & 0.116 & 0.733 \\
\hline Impulsive & $156(87.2)$ & $181(88.3)$ & & \\
\hline Planned & $23(12.8)$ & $24(11.7)$ & & \\
\hline Psychiatric follow-up & & & 0.385 & 0.535 \\
\hline Yes & $45(25.1)$ & $46(22.4)$ & & \\
\hline No & $134(74.9)$ & $159(77.6)$ & & \\
\hline
\end{tabular}

Values are presented as mean \pm standard deviation or number (\%).

nificantly younger than those using psychotropics $(45.2 \pm$ 16.4), agricultural chemicals $(52.3 \pm 16.6)$, or household products $(47.2 \pm 14.6)(p<0.001)$.

\section{DISCUSSION}

One major finding of this study is that psychotropics were the drugs ingested most frequently by SAs. SAs who used psychotropics to overdose were more likely than those who used non-psychotropics to overdose to be female, have a psychiatric history, and have a history of more previous suicide attempts. Because psychiatric disorders are major risk factors for suicide and psychotropics were a common suicide method, suicidality must be evaluated carefully when prescribing medications to patients with psychiatric disorders, especially depression.

Another important finding is that SAs frequently used sedative-hypnotics. BDZs and Z-drugs are prescribed widely in Korea and other countries. ${ }^{16)}$ Surprisingly, in Korea, BDZs are used more often to treat gastrointestinal diseases, essential hypertension, back pain, and arthropathies than to treat psychiatric disorders. ${ }^{16)}$ Family physi- cians and various specialists in primary care settings frequently prescribe Z-drugs. Although limits have been placed on the prescription of BDZs and Z-drugs in Korea, these sedative-hypnotics are still available for SAs. Therefore, primary care physicians should also assess suicidality in patients seeking sedative-hypnotics. When suicidal intent is suspected, all patients should be referred to psychiatrists.

Doxylamine and diphenhydramine are OTC medications primarily used as hypnotics. Despite its relative safety, doxylamine can cause somnolence, coma, seizures, tachycardia, psychosis, rhabdomyolysis, acute pancreatitis, and renal failure. ${ }^{21,22)}$ Diphenhydramine, an antihistamine with sodium channel blockade properties, causes dysrhythmias, seizures, and death with overdose. ${ }^{23,24)}$ These medications are frequently ingested by SAs worldwide, probably due to their easy availability. Therefore, policies that limit the availability of OTC hypnotics may contribute to the prevention of suicide by overdose.

Assessment of the relative toxicity of the psychotropics used in overdoses can contribute to minimizing fatalities. Among antidepressants, TCAs appear to have higher 
overdose toxicity than SSRIs. ${ }^{9)}$ TCAs cause serious cardiotoxicity, respiratory depression, seizures, coma, and death. ${ }^{25,26)}$ SSRIs have a wide margin of safety and are relatively safe in overdose, although they are associated with serotonin syndrome, central nervous system (CNS) depression, seizures, and cardiac electrophysiological abnormalities, such as QTc prolongation. ${ }^{27)}$ Among SSRIs, citalopram is regarded as the SSRI with the greatest potential for causing cardiac toxicity. ${ }^{28)}$ Mirtazapine has a broad therapeutic index, and serious toxic effects are rare. ${ }^{29)}$ Mirtazapine is also relatively safe following an overdose compared with TCAs and SSRIs. ${ }^{30)}$ Recently, the prescription of bupropion has increased for major depressive disorder, bipolar II depression, and attention deficit hyperactivity disorder, its use as an adjuvant for cigarette smoking cessation has also increased due to its favorable pharmacological profile, including the absence of sexual dysfunction or drug-induced weight gain. ${ }^{31)}$ The number of bupropion overdoses is likely to increase in proportion to the increased prescription of the drug. Cases of severe bupropion overdose reported worldwide and in Korea warrant careful monitoring of suicide ideation and drug compliance, especially in adolescents. ${ }^{32-34)}$

We further investigated the characteristics of SAs who used psychotropics to overdose. The data suggested that females who had psychiatric histories attempted suicide in less risky ways characterized by lower medical severity. This suggests that some SAs do not have a real intention to die and that non-serious suicide attempts may serve functions related to self-punishment, interpersonal influence, or interpersonal boundaries. ${ }^{35)}$ A comprehensive assessment of suicidality, including the intent to die, using a measure such as the Suicide Intent Scale, may further illuminate our understanding of suicidal behavior.

Another interesting finding was that agricultural chemicals were the second most frequently ingested substances. As the hospital where this study was conducted is located in a suburban area close to a rural area, this finding cannot be generalized. Nevertheless, there is a considerable likelihood of serious systemic sequelae or death following ingestion of these chemicals. ${ }^{36,37)}$ Advancing age is also associated with a poor prognosis. ${ }^{38)}$

In this study, analgesics were the drugs ingested most frequently by young SAs. Approximately half (30/62) the SAs who ingested analgesics were younger than 29 years. Post-hoc ANOVA revealed that the age of SAs who ingested analgesics (30.4 \pm 11.7$)$ was significantly lower than that of SAs using psychotropics (45.2 \pm 16.4$)$, agricultural chemicals $(52.3 \pm 16.6)$, or household products $(47.2 \pm$
14.6) $(p<0.001)$. This is consistent with reports that young adolescents ingested analgesics and that elderly individuals used pesticides as means of attempting suicide. ${ }^{10,11)}$

Although this study provides many important insights related to suicide research, several limitations should be mentioned. First, excluding patients who were not able to participate in an appropriate psychiatric interview due to a serious medical condition or suicide completion may have caused selection bias. Second, as this study was performed at a university hospital located in a suburban area, caution should be used when generalizing the study findings. Third, this study included only the principal diagnosis. It is difficult to correctly diagnose a personality disorder based on a brief interview, and the limited information available in an ED may cause misdiagnosis and bias.

In conclusion, psychotropics comprised a significant proportion of the drugs ingested by SAs. Appropriate assessment of suicidality in psychiatry patients and careful monitoring of compliance may be needed.

\section{REFERENCES}

1. Anestis MD, Anestis JC. Suicide rates and state laws regulating access and exposure to handguns. Am J Public Health 2015;105:2049-2058.

2. Biddle L, Donovan J, Owen-Smith A, Potokar J, Longson $\mathrm{D}$, Hawton $\mathrm{K}$, et al. Factors influencing the decision to use hanging as a method of suicide: qualitative study. $\mathrm{Br} J$ Psychiatry 2010;197:320-325.

3. Myung W, Lee GH, Won HH, Fava M, Mischoulon D, Nyer $\mathrm{M}$, et al. Paraquat prohibition and change in the suicide rate and methods in South Korea. PLoS One 2015;10:e0128980.

4. Oh SH, Lee KU, Kim SH, Park KN, Kim YM, Kim HJ. Factors associated with choice of high lethality methods in suicide attempters: a cross-sectional study. Int J Ment Health Syst 2014;8:43.

5. Shields LB, Hunsaker DM, Hunsaker JC 3rd, Ward MK. Toxicologic findings in suicide: a 10-year retrospective review of Kentucky medical examiner cases. Am J Forensic Med Pathol 2006;27:106-112.

6. Centers for Disease Control and Prevention (CDC). Toxicology testing and results for suicide victims--13 states, 2004. MMWR Morb Mortal Wkly Rep 2006;55:1245-1248.

7. Buckley NA, Whyte IM, Dawson AH, McManus PR, Ferguson NW. Self-poisoning in Newcastle, 1987-1992. Med J Aust 1995;162:190-193.

8. Sinyor M, Howlett A, Cheung AH, Schaffer A. Substances used in completed suicide by overdose in Toronto: an observational study of coroner's data. Can J Psychiatry 2012;57:184-191.

9. Flanagan RJ. Fatal toxicity of drugs used in psychiatry. Hum Psychopharmacol 2008;23 Suppl 1:43-51.

10. Kweon YS, Hwang S, Yeon B, Choi KH, Oh Y, Lee HK, et al. Characteristics of drug overdose in young suicide attempters. Clin Psychopharmacol Neurosci 2012;10:180-184.

11. Kim YR, Choi KH, Oh Y, Lee HK, Kweon YS, Lee CT, et al. Elderly suicide attempters by self-poisoning in Korea. Int Psychogeriatr 2011;23:979-985.

12. Osváth P, Fekete S. Characteristics of the choice of 
psychotropic drugs in suicide attempts. Orv Hetil 2003;144: 121-124.

13. Michel K, Waeber V, Valach L, Arestegui G, Spuhler T. $A$ comparison of the drugs taken in fatal and nonfatal selfpoisoning. Acta Psychiatr Scand 1994;90:184-189.

14. Carlsten A, Waern M. Are sedatives and hypnotics associated with increased suicide risk of suicide in the elderly? BMC Geriatr 2009;9:20.

15. Ekedahl A, Lidbeck J, Lithman T, Noreen D, Melander A. Benzodiazepine prescribing patterns in a high-prescribing Scandinavian community. Eur J Clin Pharmacol 1993;44: 141-146.

16. Oh SH, Oh KS, Lee KU, Woo JM, Lee BC, Hwang JS, et al. In-depth investigation for prescribing trends of benzodiazepines in South Korea. Int J Clin Pharmacol Ther 2014;52: 460-470.

17. Association Psychiatric Association. Diagnostic and statistical manual of mental disorders, 4th edition, text revision. Washington DC:American Psychiatric Association;2000.

18. Misson H, Mathieu F, Jollant F, Yon L, Guillaume S, Parmentier C, et al. Factor analyses of the Suicidal Intent Scale (SIS) and the Risk-Rescue Rating Scale (RRRS): toward the identification of homogeneous subgroups of suicidal behaviors. J Affect Disord 2010;121:80-87.

19. Weisman $\mathrm{AD}$, Worden JW. Risk-rescue rating in suicide assessment. Arch Gen Psychiatry 1972;26:553-560.

20. Linehan MM, Comtois KA, Brown MZ, Heard HL, Wagner A. Suicide Attempt Self-Injury Interview (SASII): development, reliability, and validity of a scale to assess suicide attempts and intentional self-injury. Psychol Assess 2006; 18:303-312.

21. Lee YD, Lee ST. Acute pancreatitis and acute renal failure complicating doxylamine succinate intoxication. Vet Hum Toxicol 2002;44:165-166.

22. Kim HJ, Oh SH, Youn CS, Wee JH, Kim JH, Jeong WJ, et al. The associative factors of delayed-onset rhabdomyolysis in patients with doxylamine overdose. Am J Emerg Med 2011;29:903-907.

23. Eckes L, Tsokos M, Herre S, Gapert R, Hartwig S. Toxicological identification of diphenhydramine (DPH) in suicide. Forensic Sci Med Pathol 2013;9:145-153.

24. Abdi A, Rose E, Levine M. Diphenhydramine overdose with intraventricular conduction delay treated with hypertonic sodium bicarbonate and i.v. lipid emulsion. West J Emerg Med 2014;15:855-858.

25. Woolf AD, Erdman AR, Nelson LS, Caravati EM, Cobaugh
DJ, Booze LL, et al. Tricyclic antidepressant poisoning: an evidence-based consensus guideline for out-of-hospital management. Clin Toxicol (Phila) 2007;45:203-233.

26. Choi KH, Lee KU. Serial monitoring of lead aVR in patients with prolonged unconsciousness following tricyclic antidepressant overdose. Psychiatry Investig 2008;5:247-250.

27. Nelson LS, Erdman AR, Booze LL, Cobaugh DJ, Chyka PA, Woolf $\mathrm{AD}$, et al. Selective serotonin reuptake inhibitor poisoning: An evidence-based consensus guideline for outof-hospital management. Clin Toxicol (Phila) 2007;45:315332.

28. Isbister GK, Bowe SJ, Dawson A, Whyte IM. Relative toxicity of selective serotonin reuptake inhibitors (SSRIs) in overdose. J Toxicol Clin Toxicol 2004;42:277-285.

29. Wenzel S, Aderjan R, Mattern R, Pedal I, Skopp G. Tissue distribution of mirtazapine and desmethylmirtazapine in a case of mirtazapine poisoning. Forensic Sci Int 2006;156: 229-236.

30. Choi KH, Lee KU. Over-sedation, the main toxic effect of mirtazapine overdose? Clin Psychopharmacol Neurosci 2010;8:167-169.

31. Stahl SM, Pradko JF, Haight BR, Modell JG, Rockett CB, Learned-Coughlin S. A review of the neuropharmacology of bupropion, a dual norepinephrine and dopamine reuptake inhibitor. Prim Care Companion J Clin Psychiatry 2004;6:159-166.

32. Shepherd G, Velez LI, Keyes DC. Intentional bupropion overdoses. J Emerg Med 2004;27:147-151.

33. Lewis JC, Sutter ME, Albertson TE, Owen KP, Ford JB. An 11-year review of bupropion insufflation exposures in adults reported to the California Poison Control System. Clin Toxicol (Phila) 2014;52:969-972.

34. Choi KH, Kyong YY, Lee KU. Two cases of severe bupropion overdose. Clin Psychopharmacol Neurosci 2010;8:49-52.

35. Klonsky ED. The functions of deliberate self-injury: a review of the evidence. Clin Psychol Rev 2007;27:226-239.

36. Bradberry SM, Proudfoot AT, Vale JA. Glyphosate poisoning. Toxicol Rev 2004;23:159-167.

37. Thakur DS, Khot R, Joshi PP, Pandharipande M, Nagpure $\mathrm{K}$. Glyphosate poisoning with acute pulmonary edema. Toxicol Int 2014;21:328-330.

38. Kim YH, Lee JH, Hong CK, Cho KW, Park YH, Kim YW, et al. Heart rate-corrected QT interval predicts mortality in glyphosate-surfactant herbicide-poisoned patients. Am J Emerg Med 2014;32:203-207. 